Encontros Bibli: revista eletrônica de biblioteconomia e ciência da informação, v. 17, n. esp.1, p. 110-124, 2012. ISSN 1518-2924. DOI: 10.5007/1518-2924.2012v17nesp1p110

\title{
A INTERVENÇÃO HUMANA NA QUALIFICAÇÃO DE PROCESSOS DE DATA MINING: ESTUDO DE CASO EM UMA BASE DE DADOS HIPOTÉTICA
}

\author{
Juliano Tonizetti Brignoli ${ }^{\mathrm{i}}$ \\ Egon Sewald Juniorii \\ Viviane Brandão Miguez ${ }^{\text {iii }}$ \\ Neri dos Santos ${ }^{\text {iv }}$ \\ Fernando Spanhol $^{\mathrm{v}}$
}

Resumo: Este artigo explora argumentações acerca das contribuições da intervenção de analistas humanos em processos de Data Mining. A eficiência algorítmica destes processos não é suficiente na busca por conhecimento voltado ao apoio decisório em domínios com natureza de informação complexa e volumosa. Propriedades da intelectualidade humana, como a inferência e a percepção propiciam excelente complementação aos processos de análise de dados. Por meio de estudo de caso baseado em simulação pretende-se validar proposições que asseguram o fato dos processos de Data Mining serem conduzidos e interpretados por analistas humanos, tornando-os assim, de característica dinâmica.

Palavras-chave: Data Mining. Psicologia Cognitiva. Conhecimento.

HUMAN INTERVENTION IN QUALIFYING PROCESS DATA MINING: A CASE STUDY IN A DATABASE HYPOTHETICAL

Abstract: This article explores arguments about the contributions of the intervention of human analysts in data mining processes. The algorithmic efficiency of these processes is not enough in the pursuit of knowledge dedicated to support decision making in areas with nature complex and voluminous information. Properties of human intellectuality, as inference and perception provide excellent complement to the processes of data analysis. Through case study-based simulation is intended to validate propositions that ensure the fact that the processes of data mining being conducted and interpreted by human analysts, thereby making them, the dynamic characteristic.

Keywords: Data Mining. Cognitive Psychology. Knowledge.

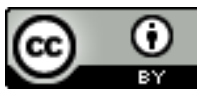

Esta obra está licenciada sob uma Licença Creative Commons

\footnotetext{
${ }^{\mathrm{i}}$ Universidade Federal de Santa Catarina.juliano.brignoli@gmail.com.

${ }^{\mathrm{ii}}$ Universidade Federal de Santa Catarina. egonsj@gmail.com.

${ }^{i i i}$ Universidade Federal de Santa Catarina. vivianemiguez@gmail.com.

${ }^{\text {iv }}$ Universidade Federal de Santa Catarina. neri@egc.ufsc.br.

vUniversidade Federal de Santa Catarina. spanhol@led.ufsc.br.
} 


\section{INTRODUCÃO}

Frente as necessidades informacionais da atual conjuntura sócio-econômica a automação dos processos de análise e inferência sob volumosos conjuntos de dados nas organizações tem proporcionado contribuições significativas no que refere-se ao apoio em atividades decisórias. Aliadas ao fator eficiência computacional, especificamente em tratandose do tempo, culminam como quisito primordial para qualificar ações de busca por indicadores de suporte a gestão, inovação, percepção das tendências de mercado e tantos outros fatores indispensáveis para a sobrevivência e sustentabilidade das organizações no contexto da sociedade do conhecimento.

No âmbito da automação referida encontram-se as técnicas matemáticas e computacionais que convergem para a formação dos denominados KDD (Knowledge Data Discovery), que compreendem algoritmos computacionais, apoiados por formulações matemáticas e estatísticas, voltados à aplicações que suportam processos analíticos complexos, os quais exigiriam esforço cognitivo individual ou, na maioria das situações, uma cooperação mútua coletiva de perítos no domínio do problema em questão.

É notável que a eficiência computacional destes algoritmos de KDD são necessárias para cenários de análise de dados complexos, porém, não são suficientes para assegurar confiança significativa em termos da geração de resultados com qualidade e acurácia. Em contraposição, a eficiência do processamento analítico humano em termos da utilização de todo o nosso aparato cognitivo não apresenta as mesmas condições de toda a rentabilidade dada pela agilidade dos algoritmos computacionais de KDD, mas, oferece capacidades de análise e inferência munidas de doses de sensatez que ainda não foram reproduzidas artificialmente em termos computacionais, ou seja, a automação ainda é desprovida de qualidades humanas de discernimento.

Diante desta argumentação, é oportuno investigar as oportunidades de contribuição dos especialistas humanos para aprimorar as próprias técnicas de KDD, intervindo no ciclo do processamento analítico de informações organizacionais de modo a potencializar a inferência e o processo de geração de conhecimento, inserindo melhor veracidade nos resultados almejados pelas perguntas de pesquisa ou consultas aplicadas sob as bases informacionais.

A proposição deste artigo é discorrer sobre a caracterização das técnicas de KDD, especificamente elucidando a utilização dos algoritmos de Data Mining, compreender o sistema de processamento informacional humano e, analisar como esta capacidade cognitiva 
humana pode fazer intervenções nos processos automatizados propostos pelo Data Mining em prol da adoção de uma melhor qualificação dos resultados assegurando a disponibilização de cenários de informação mais propensos a tomada de decisão humana. Para validar a conceituação abordada e as argumentações acerca da intervenção de especialistas humanos nos processos automatizados de Data Mining propõe-se uma análise sob a forma de estudo de caso aplicado em uma base de dados hipotética.

\section{CARACTERIZAÇÃO DOS PROCESSOS DE DATA MINING}

A evolução das técnicas computacionais de análise de dados em consonância com as demandas da gestão organizacional na conjuntura da sociedade do conhecimento culminaram na elaboração de sofisticados algorítmos que suportam processos analíticos sobre conjuntos volumosos e de natureza informacional complexa. Murray et al. (2005, p.415) retratam em seu artigo o surgimento da necessidade de se fazer Descoberta de Conhecimento por meio da automaticidade e elucidam a forte dependência desta aquisição de conhecimento por meio da automação. $\mathrm{O}$ autor discorre sobre as necessidades organizacionais ao se referir a processos de aquisição, interpretação e aplicação prática realizada sobre dados minerados. Algumas teorias têm contribuído significativamente para o surgimento de algoritmos automatizados de Data Minig, tais como, Banco de Dados, a Teoria dos Conjuntos, técnicas oriundas dos estudos da Inteligência Artificial e ainda, a inserção de formulações matemáticas e estatísticas para a realização de operações de correlação entre dados. Diante de todo este arcenal de técnicas e proposições existem várias definições e qualificações que convergem para conceituar processos de Data Minig. Cardoso \& Machado (2008, p. 497) afirmam:

Data mining, ou mineração de dados, é uma técnica que faz parte de uma das etapas da descoberta de conhecimento em banco de dados. Ela é capaz de revelar, automaticamente, o conhecimento que está implícito em grandes quantidades de informações armazenadas nos bancos de dados de uma organização. Essa técnica pode fazer, entre outras, uma análise antecipada dos eventos, possibilitando prever tendências e comportamentos futuros, permitindo aos gestores a tomada de decisões

baseada em fatos e não em suposições.

Segundo Murray et al. (2005, p.415), as necessidades organizacionais de cinquenta anos atrás não apresentavam a mesma complexidade das atuais em termos da formulação do tipo de pergunta de pesquisa aplicável sobre uma base de dados. Esta argumentação é pertinente ao se verificar alguns exemplos reais encontrados, tais como se pode elucidar por meio do seguinte cenário: 
O supervisor do departamento de vendas de uma determinada empresa do setor de varejo, com base nos registros de vendas dos últimos períodos mensais deseja saber: qual será o comportamento das vendas para os próximos seis meses?

É evidente que esta pergunta sugere a utilização de técnicas e ferramentas para análise de tendências e dispõe de uma oportunidade para a aplicação dos processos de Data Mining.

É importante evidenciar nesta abordagem inicial que a pergunta elaborada no cenário acima simplificado pode ser respondida simplesmente a partir da aplicação de um algorítmo computacional que implemente, por exemplo, uma análise de séries temporais. Porém, dependendo da complexidade da pergunta, da dispersão dos dados e do volume da base, o emprego de ferramentas automatizadas de Data Mining por sí só pode não resultar na geração de indicadores de apoio a tomada de decisão com uma semântica e acurácia almejada, ou seja, os resultados podem não convergir para uma real situação em que um períto humano assim os interpretaria de modo diferente. Este último argumento está alinhavado com a proposição principal apresentada no início deste artigo, a qual pretende discorrer sobre as contribuições dos especialistas humanos nos processos de Data Mining para melhor refinar ou qualificar os resultados destes processos e gerar indicadores e conhecimentos que imprimem a real situação de uma necessidade organizacional.

As técnicas de Data Mining fazem parte dos processos genéricos de KDD e todo este arsenal tecnológico, têm contribuído para a gestão da informação e do conhecimento no contexto da aplicação do denominado BI (Business Intelligence). A figura 1 ilustra o enquadramento operacional do Data Mining em termos da aplicação do conjunto de ferramentas de BI: 
Figura 1 - Data Mining como ferramenta integrante em BI

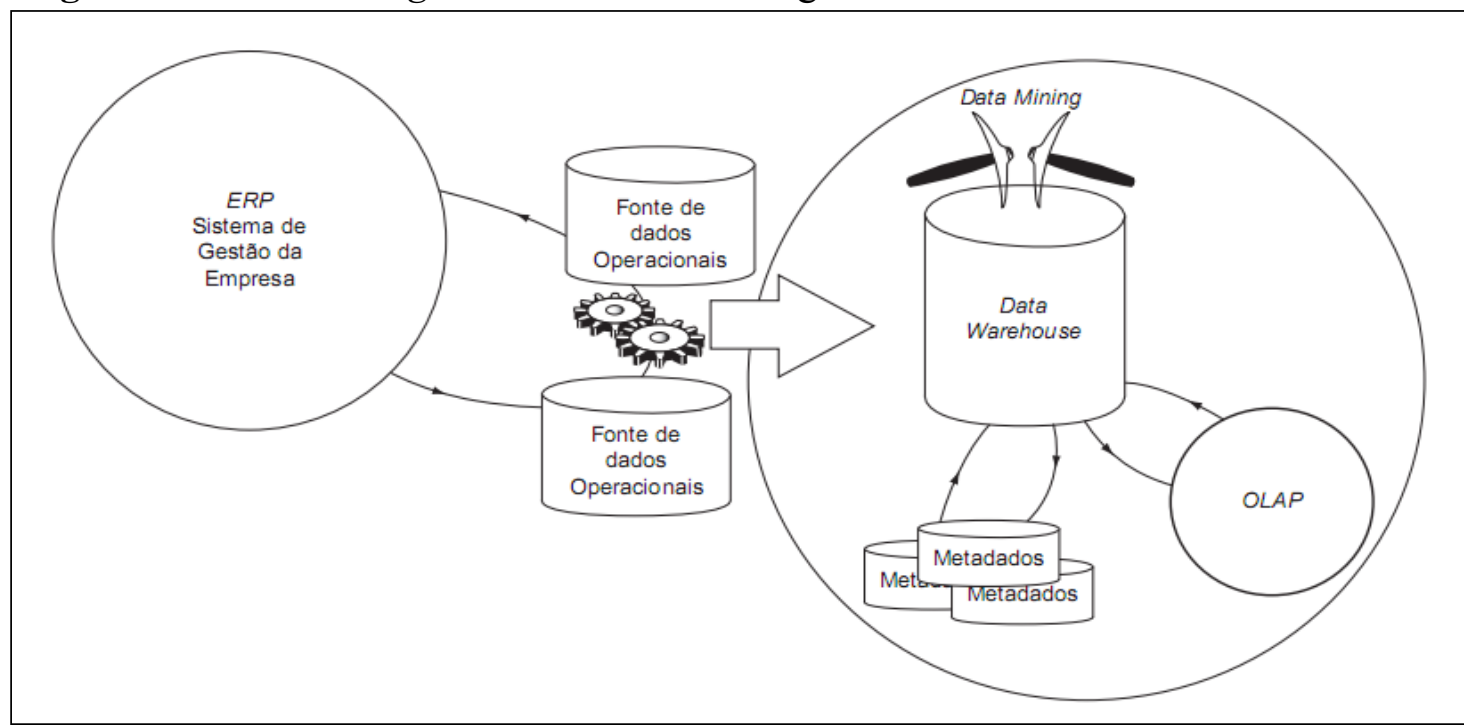

Fonte: Fortulan \& Filho, 2005, p.57

Os processos de Data Mining consistem, de uma maneira conceitual e genérica, basicamente em três estágios:

1. Estágio da exploração;

2. Estágio da construção do modelo ou da definição do padrão;

3. Estágio da validação: neste, são empregados algoritmos computacionais de Segmentação, Classificação e Previsão.

Por tratar-se de uma ferramenta caracterizada principalmente pelo suporte a construção de indicadores de apoio a decisão humana, o Data Mining em conjunto com outros processos de KDD realizam a denominada Análise Exploratória, pela qual, o usuário da ferramenta objetiva descobrir novos conhecimentos contidos em uma base de dados por meio de processo analítico. Esta exploração também se apoia na contrução ou representação visual de resultados processados. O estudo da percepção humana frente as formas de visualização da informação têm discorrido em contribuições importantes para o emprego das técnicas de KDD em consonância com os aspectos da interpretação humana sob a análise de dados. Alexandre \& Tavares (2007, p.5), ao estudar as características da percepção humana na visualização dos dados retrataram uma análise da Teoria Gestald e afirmam:

Uma das teorias da percepção mais largamente conhecida e adoptada em várias áreas, é a da Gestalt. A Teoria da Gestalt baseia-se no seguinte princípio: Não se pode ter conhecimento do todo através das partes, e sim das partes através do todo; Que os conjuntos possuem leis próprias e estas regem os seus elementos, e não o contrário, tal como se pensava anteriormente; E que só através da percepção da 
totalidade é que o cérebro pode de facto perceber, descodificar e assimilar uma imagem ou um conceito.

É conveniente citar no contexto das ferramentas de KDD, correlatas ao propósito dos algoritmos de Data Mining a utilização de técnicas de OLAP (On-Line Analytical Processing) que também contribuem para a organização de indicadores de apoio a decisão sobre volumosos conjuntos de dados em múltiplas perspectivas de usuário. (VREMBEL, 2006, p.90).

De fato, processos de Data Mining, potencializados pela agregação de múltiplos conceitos e técnicas oferecem uma eficiente ferramenta em contribuição a análise de dados e exploração de conhecimento. Contudo, a descoberta de padrões com maior grau de complexidade dificulta a obtenção de resultados mais qualificados semanticamente. Em seu artigo, Loureiro (2011) argumenta que:

Data Mining ainda requer uma interação muito forte com analistas humanos, que são, em última instância, os principais responsáveis pela determinação do valor dos padrões encontrados.

O autor discorre ainda que a condução do processo de exploração dos dados deve ser confiada aos especialistas humanos e que isso é fundamental para o sucesso de qualquer projeto que empregue as técnicas de automação.

A opinião de Loureiro (2011) vêm reforçar a proposição deste artigo e contribuir com a argumentação de Murray et al. (2005, p.415) ao analisarem as contraposições entre os processos automatizados e a intervenção humana nas aplicações que utilizam os processos de Data Mining.

Os capítulos subsequentes irão abordar de modo mais pontual as questões da empregabilidade desta intervenção humana aos processos de Data Mining.

\section{ASPECTOS COGNITIVOS DO PROCESSAMENTO ANALÍTICO HUMANO}

Os estudos da Psicologia Cognitiva têm contribuído significativamente para a compreensão acerca das características do nosso sistema de memorização, aprendizado, análise e demais fatores associados às capacidades da intelectualidade humana. Em termos tecnológicos estes estudos cooperaram para a reprodução de artefatos que objetivaram a emulação do comportamento inteligente humano, originando, por exemplo, na área de 
Inteligência Artificial e toda sua diversidade algorítmica para resolver problemas vinculados ao reconhecimento de padrões, indução, inferência, entre inúmeros outros.

Ao longo do desenvolvimento das pesquisas no campo da cognição e automação do raciocínio humano surgiram várias proposições teóricas para explicar ou emular o processo de inferência humana. Para exemplificar, é notória a própria Lógica e todo seu formalismo matemático que oferece maneiras de se alcançar resultados por meio de algoritmos de indução, tableaux, etc. (BALBIANI, et al, 2008, 57). A Inteligência Artificial propôs seus complexos algoritmos para o reconhecimento de padrões inspirados nas características do nosso sistema neuronal. Contudo, entre estas e outras abordagens teóricas elaboradas no intuito de aproximar sistemas automatizados das habilidades cognitivas humanas ainda se apresenta um panorama de pouca eficácia em termos da qualidade dos resultados de análises de dados realizadas por algoritmos. Talvez pelo fato de toda teoria ser reducionista é plausível que minuciosos detalhes sobre a operacionalização da inferência humana não sejam considerados nas implementações destas ferramentas automatizadas de análise. Este argumento sugere a existência de uma lacuna entre o arsenal tecnológico e a real capacidade de discernimento do analista humano. Se por um lado, as tecnologias que automatizam processos de inferência apresentam eficiência computacional, por outro, são limitadas diante de situações em que haja um alto grau de complexidade nas relações existentes entre as variáveis que modelam o problema em questão. Murray et al. $(2005$, p.416) discorre em seu artigo sobre o Sistema de Processamento de Informação dos humanos e cita algumas características do mesmo:

- Extração dos dados do ambiente externo;

- Detecção de padrões;

- Manutenção ou rejeição de informações relativas ao contexto;

- Processamento as informações em "alto nível” (significado das palavras);

- Realizar conclusões;

- Engajar comportamento;

- Um sistema dinâmico, complexo, de processamento inferencial rápido e passível de erros.

Esta última característica enfatiza a cognição humana como parte integrante de todo um sistema dinâmico de capacidade para processamento de informação. Este dinamismo não é uma característica consolidada nos sistemas de Data Mining, pois estes realizam operações 
de análise de dados com parâmetros pré-determinados, do início ao fím do processo de mineração. Murrey et al. (2005, p.416) propõe que haja a oportunidade dos processos de Data Mining serem dinâmicos e sugere para tal a intervenção do analista humano para guiar o processo.

Tratando-se ainda deste sistema complexo que poder-se-ia chamar de aparelho cognitivo humano é relevante abordar as características da memória. Murray et al. (2005, p.417) aborda em seu artigo a estrutura do sistema de memória humano proposta por Atkinson \& Shiffrin (1971. p.2-5) a qual descreve a seguinte arquitetura:

- Memória sensorial: armazenamento de memória breve onde a informação sensorial é inicialmente detida para processamento posterior;

- Memória de curto prazo: componente consciente do sistema de memória, limitada em termos de capacidade e duração do processamento da informação;

- Memória de longo prazo: memória permanente, as informações de curto prazo são transferidas à memória de longo prazo, pela qual se dá o armazenamento de conhecimentos.

Baddeley (2000, p.419) conceitua a memória de curto prazo como sendo uma Memória de Trabalho e esta apresenta as seguintes características:

- Reflete melhor os processos de alto nível;

- Controla recursos de atenção e execução de habilidades complexas;

- Coordena as atividades de dois sistemas chamados de "slave" (escravo), o articulatory loop (loop articulatório) e o visuospatial sketchpad (alça visuo espacial):

- articulatory loop: responsável pelo ensaio verbal da informação (repetese um número de telefone o suficiente para poder discá-lo, por exemplo);

- alça visuo espacial: manipula a informação visual (refaz os passos tentando encontrar um ponto perdido);

- curto armazenamento sensorial temporário mas altamente ativa e consciente de que está manipulando a informação.

Outras descrições pertinentes a compreensão do sistema de processamento de informação dos humanos, segundo Murray et al. (2005, p.418) são: 
- Estes sistemas possuem componentes interativos: funcionam de forma paralela, as informações não entram para percepção em forma de um fluxo simples e contínuo, mas como um sistema dinâmico e que há sobreposição entre as fases de processamento;

- Alta habilidade inferencial: permite que os indivíduos compreendam informação que não foi explicitamente experimentada ou armazenada como um fato.

$\mathrm{Na}$ sequência será abordada a idéia central da proposta deste artigo elucidando a contribuição das intervenções do analista humano no processo de mineração e análise de dados frente às habilidades do aparelho cognitivo humano. Novas conceituações a partir da Psicologia Cognitiva são evidenciadas para melhor relacionar a proposta da adoção do dinamismo aos processos de Data Mining.

\section{O CONHECIMENTO A PARTIR DA INTERVENÇÃO HUMANA SOB OS PROCESSOS DE DATA MINING}

No processo de Data Mining "tradicional” o humano responsável pela construção do modelo - dentro dos estágios conceituais apresentados anteriormente - participa de forma efetiva dos processos. Observa-se, no entanto, neste cenário, que o humano não interfere em momento algum a execução do algoritmo, que, diversas vezes, pode ser executado em forma de "caixa preta", ou seja, os raciocínios utilizados para a descoberta são desconhecidos, apesar dos algoritmos e métodos serem.

Comparando o raciocínio automatizado de Data Mining com o raciocínio humano, observa-se diferenças entre a linearidade das formas automatizadas versus dinamismo encontrado no raciocínio humano.

Murray et al. (2005, p.418) observa que, no processo de descoberta, após a elaboração do modelo, a parametrização de algoritmos permanece fixa durante todo o trabalho e aponta o não aproveitamento do raciocínio dinâmico do humano no processo de conhecimento. Caso seja aproveitado o raciocínio dinâmico do analista durante o processo, o sistema de descoberto seria, portanto, também dinâmico. Sobre o raciocínio humano observamos um dinamismo maior, porém uma memória de trabalho - memória de curto prazo - limitada, tornando-o incapaz de realizar inferências e descoberta de conhecimento, sem uso de outras ferramentas, em uma base de dados complexa ou extensa. 
Por sua vez, como apresentado, o raciocínio automatizado é linear, porém tem vasta memória de trabalho, sendo capaz de realizar inferências em um volume grandioso de dados, muitas vezes complexo.

O aproveitamento do dinamismo do raciocínio humano e a memória de trabalho automatizada poderia gerar sistemas de descoberta de conhecimento com funcionamento superiores aos atuais, porém existe a necessidade de desenvolvimento de uma interface entre o humano e a máquina.

A solução apontada por Murray et al. (2005, p.419) é a aplicação de uma abordagem visual, onde o acompanhamento do processo seria com uso de gráfico, formando um cockpit de acompanhamento das etapas e possibilitando uma intervenção durante o processo de análise dos dados.

A solução apresentada também aponta o uso da Psicologia Cognitiva na formação desta interface, considerando que: "a visualização de qualquer abordagem deve levar em consideração as limitações da memória de trabalho humana no que diz respeito à duração, capacidade e recursos atencionais" (tradução dos atores). Segundo Matlin (2004, p.10), a Psicologia Cognitiva tem como preocupação o estudo dos processos cognitivos, sendo eles percepção, pensamento, memória, imaginação, linguagem, raciocínio e tomadas de decisão.

Com base neste cenário a Psicologia Cognitiva auxilia na formação de interfaces que respeitam limitações de memória de trabalho (neste caso viso-espacial), percepção (utilizando gráficos, símbolos e cores que chamem a atenção em caso de desvios e/ ou níveis de indicadores), com objetivo de facilitar o raciocínio do usuário, de forma que este possa ser auxiliado para a tomada de decisão.

Preece et al. (1994, p.305), por sua vez afirma que a Psicologia Cognitiva beneficia o projeto de sistemas computacionais:

- por proporcionar conhecimento sobre o usuário;

- pela identificação e explanação das naturezas e causas dos problemas que os usuários encontram;

- por proporcionar a modelagem de ferramentas e métodos que auxiliam na construção de interfaces mais fáceis de usar.

Para Souza (1998, p.67) a Psicologia Cognitiva pode contribuir para uma análise mais eficaz sobre o usuário e a sua tarefa, tendo em vista a elaboração de interfaces e ferramentas de interação mais adaptadas ao usuário e à sua tarefa. 


\section{ESTUDO DE CASO: ANÁLISE DA PROPOSIÇÃO SOB UMA BASE DE DADOS HIPOTÉTICA}

Para o estudo de caso será aplicado uma massa de dados hipotética, representando uma população de materiais a serem classificados através de clusters, levando em consideração altura e peso do material. Os dados serão preparados e processados em uma rede neuronal utilizando o software MathLab.

Observa-se, inicialmente, a intervenção humana durante a fase de preparação dos dados, limpeza e carga. Os dados serão carregados em uma matriz. A figura 2 ilustra por meio de um diagrama de dispersão as entradas na matriz:

Figura 2 - Plotagem dos pontos antes de classificação

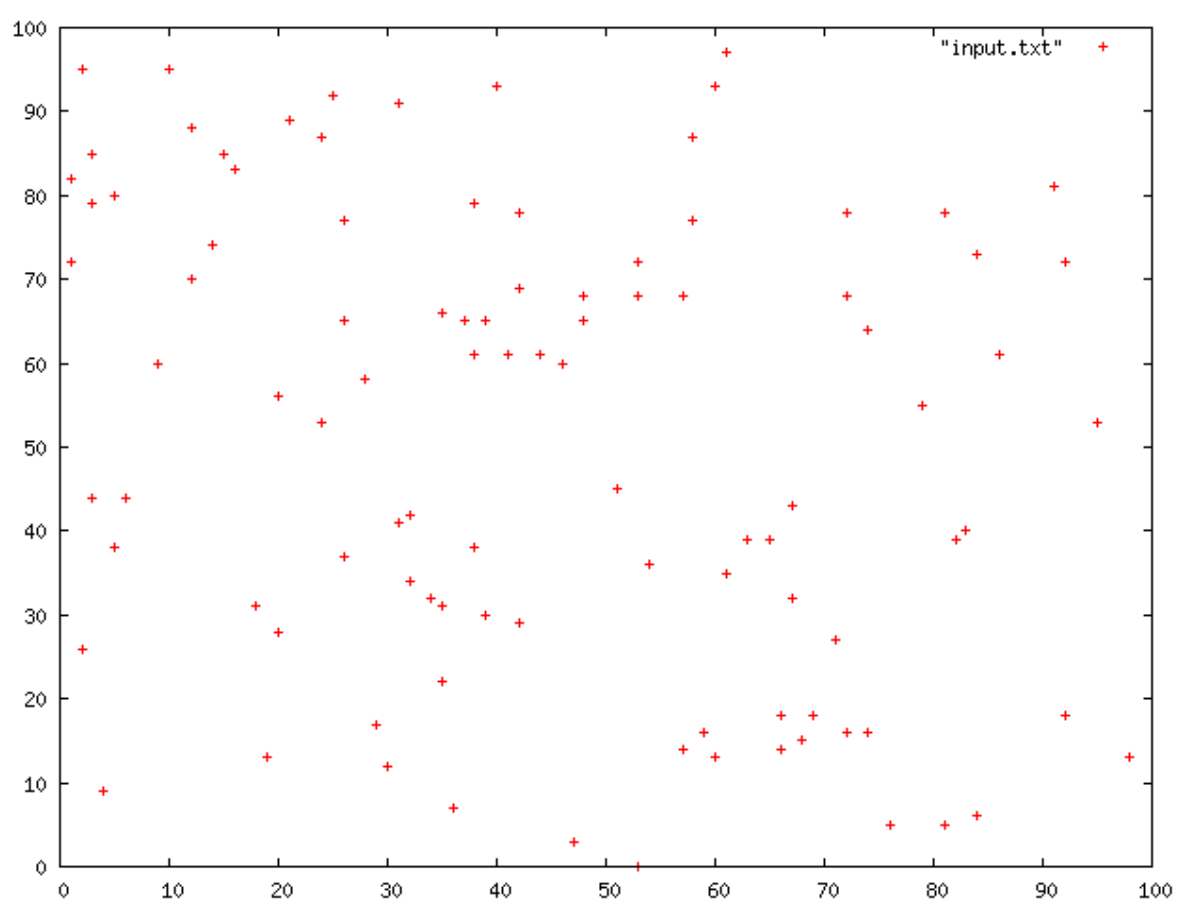

Fonte: Acervo dos autores

Após carregar as informações, o usuário deve criar a rede neuronal, de forma descobrir o conhecimento "escondido" pelo volume da massa de dados. Para criar a rede, são necessárias a escolha do algoritmo, a definição de parâmetro, e apontar para a base de dados preparada anteriormente, e realizar o treinamento, que vai ajustar os pesos entre as sinapses de forma a carregar o conhecimento necessário para, neste caso de clusterização, efetuar a classificação. 
Para esta rede neuronal para classificação em clusters, utilizaremos o algoritmo Kohonen (rede competitiva), onde o treinamento é não supervisionado - o treinamento é feito sem que exista uma massa de dados já classificada (sem intervenção humana), sendo os pesos ajustados através de interações temporais e novos ajustes, de forma a estabilizar em um espaço de tempo (ou alcançar o número de épocas de treinamento). Nesse algoritmo, cada neurônio aprende a responder maximamente a diferentes valores de entrada, ou seja, numa massa de dados plotadas em um gráfico de dispersão, procura centros que diminuam a distancia dos pontos dentro da "classe" que o neurônio responde, e aumente a distância entre as classes (excitação central - inibição lateral). O MathLab pode apresentar graficamente (figura 3) as interações e posicionamento do "centro" do cluster conforme as épocas e com isso, o usuário pode acompanhar o ajuste.

Figura 3 - A esquerda, centros de gravidades das classes. A direita, os pontos classificados
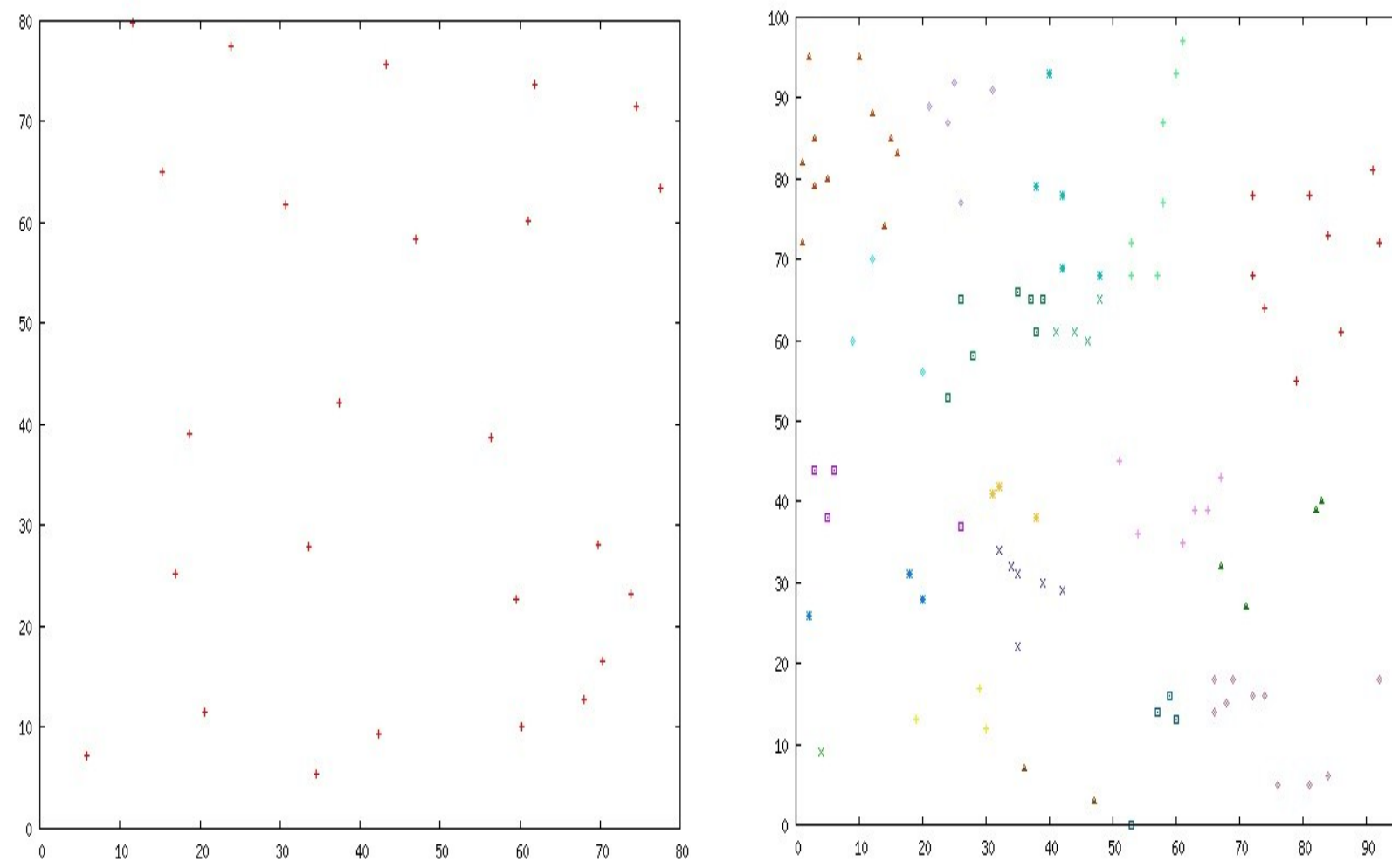

Fonte: Acervo dos autores

Porém, o MathLab não nos fornece uma interface para que, no meio da execução da rede, sejam alterados pontos que interfiram na formação da rede ou aberrações que não foram 
identificadas na limpeza dos dados. A figura 4 ilustra alterações a partir da intervenção do analista humano no processo de condução e interpretação da mineração.

Figura 4 - influências da intervenção humana sobre os resultados

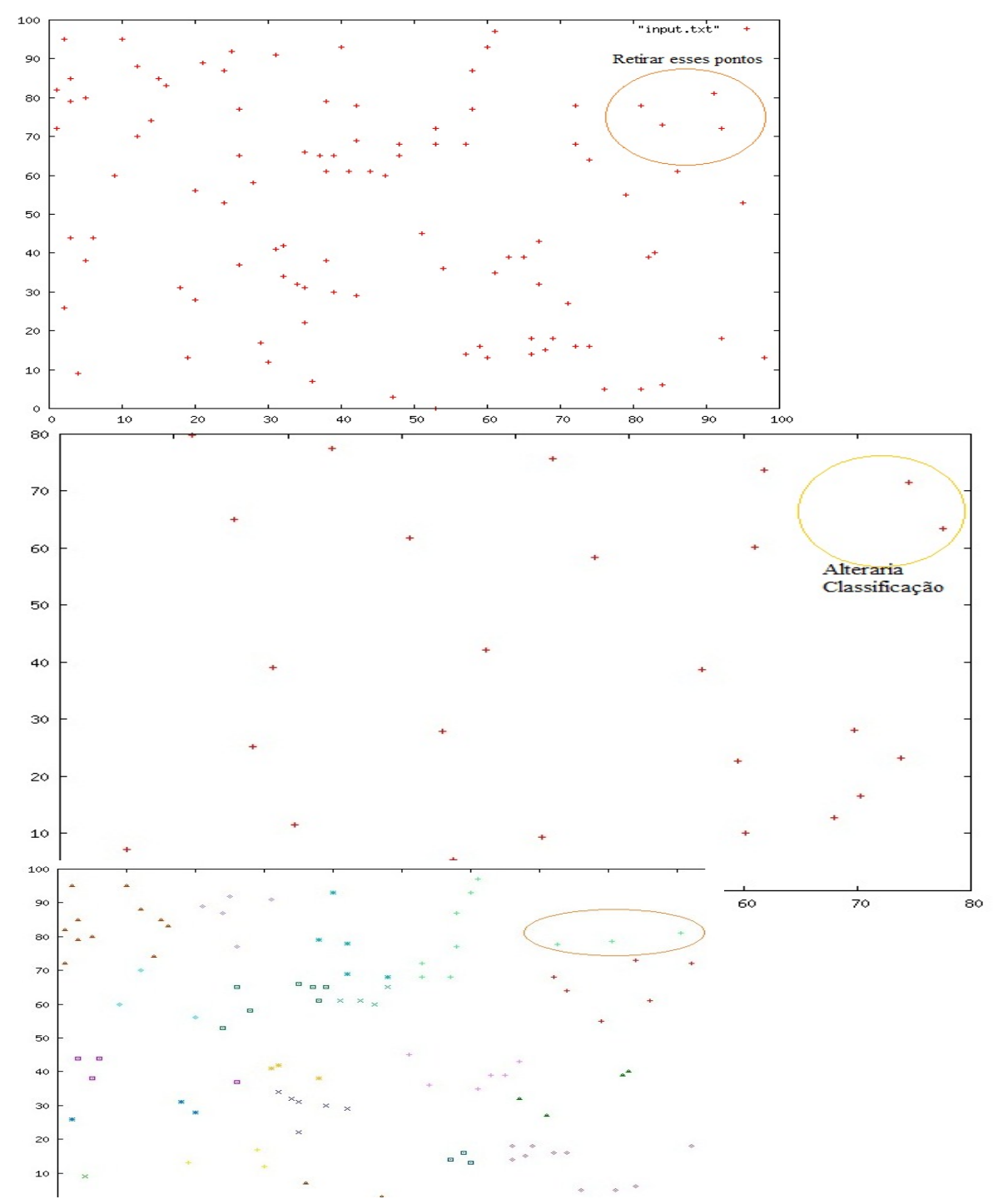

Fonte: Acervo dos autores 


\section{CONSIDERAÇÕES FINAIS}

Apesar da eficiência algorítmica dos processos de Data Mining em termos de tempo computacional, frente a volumosos e complexos conjuntos de dados, não se pode afirmar de modo convincente que estas técnicas estão consolidadas para atender às demandas e expectativas organizacionais em apoio a decisão. Em conformidade com as argumentações elucidadas por alguns autores abordados no artigo, não há dúvida quanto à necessidade da interação humana no processo de condução das etapas de uma mineração e análise de dados. A eficiência computacional não é suficiente no processo quando o cenário que retrata uma base de dados complexa apresenta situações de conflitos entre variáveis. Este é o espaço que sugere a intervenção de analistas humanos para melhor qualificar os resultados e responder às consultas parametrizadas nas etapas do Data Mining com acurácia, refletindo em respostas já pré almejadas pelas características do domínio do problema tratado.

A união das técnicas de Data Mining com a capacidade cognitiva de especialistas humanos, em especial, evidenciando a inferência e a percepção, convergem para a construção de uma ferramenta híbrida de análise de dados.

Observou-se, com a elaboração do estudo de caso que, mesmo sem o desenvolvimento de uma interface gráfica, utilizando-se de uma simulação, a mudança de pontos durante o processo interacional, incorreu no resultado final diferente do resultado inicial, cujas interações seguem apenas os parâmetros iniciais.

A contribuição da inferência humana, aproveitada durante o processamento, gerou maior dinamismo no sistema, trazendo resultados finais mais satisfatórios que retratam uma realidade, apesar de simulada.

A elaboração de uma interface gráfica certamente deverá permitir a percepção visual e em número suficientemente diminuído de elementos para que o ser humano possa utilizar sua memória de trabalho - como mostrado no estudo. A Psicologia Cognitiva apresenta bom ferramental para estudo destas interfaces, respeitando as limitações cognitivas do raciocínio humano.

Sugere-se como trabalhos futuros a aplicação da Psicologia Cognitiva no desenvolvimento de interface gráfica para que o usuário possa perceber, raciocinar e tomar a decisão, alterando o conjunto inicial, averiguando se os conhecimentos gerados, realmente são mais satisfatórios. 


\section{REFERÊNCIAS}

ALEXANDRE, Dulclerci S.; TAVARES, João M. R. S. Factores da percepção visual humana na visualização de dados. APMTAC, Portugal, 2007. Disponível em < http://repositorio-aberto.up.pt/bitstream/10216/357/2/13662.pdf $>$ Acesso em: 20/12/2011.

ATKINSON, R. C., SHIFFRIN, R. M. The control of short-term memory. Scientific American, n. 225, p. 82-90, 1971.

BADDELEY, Alan. The episodic buffer: a new component of working memory? Elsevier Science, Trends in Cognitive Sciences, v. 4, n. 11, 2000.

BALBIANI, Philippe et al. Tableaux for public Announcement Logic. Oxford, Journal of Logic and Computation, v. 20, p. 55-76, 2010.

CARDOSO, Olinda N. P.; MACHADO T. M. Gestão do Conhecimento usando Data Mining: estudo de caso na Universidade Federal de Lavras. Rio de Janeiro, FGV, Revista de Administração Pública, p. 495-528, 2008.

FORTULAN, Marcos R.; FILHO, Eduardo V. G. Uma proposta de aplicação de Business Intelligence em chão-de-fábrica. Gestão \& Produção, v.12, n.1, p. 55-66, jan./abr. 2005.

LOUREIRO, Marco A. Data Mining, conceitos e aplicabilidades. Publicações eletrônicas. Disponível em: <http://professorloureiro.com>. Acesso em: 26 de janeiro de 2011.

MATLIN, Margaret W. Psicologia Cognitiva. 5.ed. Rio de Janeiro: LTC, 2004.

MURRAY. John D.; SEVINC, Mervem; LOCKER, Lawrence. Automation vs. Human Intervention: Is There any Room Left for the Analyst in the Data Mining Process? Handbook of Research on Knowledge - Intensives Organizations. Information Science Reference. Hershey, New York, 2005.

PREECE, J., Rogers, Y., Sharp, H., Benyon, D., Holland, S. \& Carey, T. Human-Computer Interaction. Essex, England: Addison-Wesley Longman Limited, 1994

SOUZA, Delmar Carvalho de. Hipermídia aplicada ao ensino técnico de nível médio. Dissertação de Mestrado Engenharia de Produção, UFSC, Florianópolis: 1998

VREMBEL, Robert. Data Warehouses and Olap: Concepts, Architectures and Solutions. Ed. IGI Global, 2006. 